OPEN ACCESS

Edited by:

Olga Zlatkin-Troitschanskaia,

Johannes Gutenberg University

Mainz, Germany

Reviewed by:

Henry Braun,

Boston College, United States

Lucia Mason,

University of Padua, Italy

*Correspondence:

Gerhard Minnameier

minnameier@econ.uni-frankfurt.de

Rico Hermkes

hermkes@econ.uni-frankfurt.de

Specialty section:

This article was submitted to

Educational Psychology,

a section of the journal

Frontiers in Education

Received: 15 June 2020 Accepted: 03 September 2020

Published: 24 September 2020

Citation:

Minnameier $G$ and Hermkes $R$

(2020)

Learning to Fly Through Informational

Turbulence: Critical Thinking

and the Case of the Minimum Wage.

Front. Educ. 5:573020.

doi: 10.3389/feduc.2020.573020

\section{Learning to Fly Through} Informational Turbulence: Critical Thinking and the Case of the Minimum Wage

\section{Gerhard Minnameier* and Rico Hermkes*}

Chair of Business Ethics and Business Education, Faculty of Economics and Business Administration, Goethe University

Frankfurt am Main, Frankfurt, Germany

The paper addresses online reasoning and information processing with respect to a much debated issue: the pros and cons of the minimum wage. Like with all controversial issues, one can easily remain in a self-reinforcing bubble, once one has taken sides, and immunize oneself against criticism. Paradoxically, the more information we have at our disposal, the easier this gets (Roetzel, 2019). The only (and possibly universal) antidote seems to be "critical thinking" (Ennis, 1987, 2011). However, critical thinking is a very broad concept, purported to include diverse kinds of information processing, and it is also thought to be content-specific. Therefore, we aim at addressing both understanding of content knowledge and reasoning processes. We pursue three goals with this paper: First, we conduct a conceptual analysis of the learning content and of reasoning patterns for and against the minimum wage. Second, we explicate an inferential framework that can be applied for processes of critical thinking. Third, teaching strategies are discussed to support reasoning processes and to promote critical thinking skills.

Keywords: critical thinking, inferential processes, abduction, argumentation, online reasoning, multipledocument comprehension, cognitive conflict

\section{INTRODUCTION}

In the digital age, online reasoning and the processing of information from multiple sources with contradictory viewpoints are of outstanding importance. Instead of immunizing oneself against criticism and other viewpoints, one should on the one hand be open-minded. On the other hand, one should not blindly follow the opinions of others and resist manipulative information and campaigns. Critical thinking addresses this ability and is regarded as one of the key twenty first century learning and innovation skills (OECD). Oser (2018) sums it up pointedly by stating that "(c)ritical thinking is seen as a means for guarding against fake news in its psychological and emotional dimension" (p. 368). However, critical thinking is a very broad concept, purported to include diverse kinds of (generic) information processing activities, and it is also thought to be content-specific (see Ennis, 1987, 2011; Tarchi and Mason, 2020). 
How do critical thinking skills manifest themselves in situ? As Dormann et al. (2018) state, there is a consensus on the processes involved in critical thinking. The authors write:

The consensus list of critical thinking skills "[is]" comprized of six skills (sub-skills in parentheses): interpretation (categorization, decoding significance, clarifying meaning), analysis (examining ideas, detecting arguments, analyzing arguments), evaluation (assessing claims, assessing arguments), inference (querying evidence, conjecturing alternatives, drawing conclusions), explanation (stating results, justifying procedures, presenting arguments), and self-regulation (self-examination, self-correction) (p. 329f).

Consensus is fine. However, this structured list also reveals that there is still a need to further disentangle and differentiate the processes at work (as they obviously shade into each other and lack clear boundaries). Moreover, it shows that critical thinking cannot be limited to purely logical-analytical processes. According to Hitchcock (2017), "some critical thinking, but not all, is logical analysis of argument. In thinking critically, we not only want to find out, if a single piece of reasoning or argument is good or bad. We also want to know more about its context and see it in a broader framework of alternative choices, ways or options. We want to trace the best path toward our understanding of a problem and make the best decision about it. We also look at the extent to which all our judgments and decisions are supported by evidence while examining as well the quality of this evidence" ( $p$. 484). In this respect, an essential property of critical thinking is the embedding of arguments in an overall context.

Shavelson et al. (2019) differentiate between two types of contexts: (i) everyday life contexts, in which decision makingor problem solving-processes take place and (ii) argumentative contexts, in which one's own positions are to be developed and justified. Such argumentative contexts are largely formed by other people. For this reason, critical thinking is often closely associated with multiple-text-comprehension (see Stadtler and Bromme, 2013; Richter and Maier, 2017; Tarchi and Mason, 2020).

A suitable starting point for a systematization is offered by da Silva Almeida and Rodrigues Franco (2011). They state, that critical thinking "is a multifaceted cognitive construct, with an inductive, deductive and creative nature" (p. 179). On the one hand, this aims at inferences as suitable "candidates" for processes of critical thinking. On the other hand, it also goes beyond a logical-analytical framework, as Hitchcock puts it. The problem here is that "logic" is equated with deduction. However, inferences should be understood in the context of the rather new and wider program of the naturalization of logic, which is not limited to classical (deductive) logical approaches, but also includes processes of practical reasoning and eco-logical judgments in realworld contexts (Gabbay and Woods, 2005; Magnani, 2009, 2018; Minnameier, 2019). In particular, it includes abduction and induction and how they, together with deduction, shape reasoning processes in general. In this sense, logic counts as the theory of right reasoning. Understood in this way and in this wider sense, inferential reasoning is what critical thinking is mainly about (apart from non-cognitive factors that concern, e.g., self-regulation).

This is particularly important, because not only are the nature and the amount of information processed constantly changing, but so is the world, too. Consequently, the need to explain world phenomena is also evolving continuously. Finally, this also accounts for the truth of propositions about the world. As Magnani puts it, an abductive "inferential problem can be enhanced by the emergence of new information in a temporal dimension that favors the restarting of the inferential process itself" (p. 12). In this respect, as the title suggests, one can speak of "informational turbulences," through which critical thinking has to maneuver.

The paper is structured in three parts. In the first part, we conduct a conceptual analysis of the learning content in the case of the minimum wage. In the second part, we explicate an inferential framework that can be applied for assessing processes of critical thinking. We reconstruct typical reasoning patterns for and against the minimum wage and identify problems of reasoning. In the third part, teaching strategies are discussed to promote critical thinking.

\section{THE CASE OF THE MINIMUM WAGE}

\section{Content Analysis}

Minimum wages exist in many countries around the world, especially in Anglo-American and European countries, but not everywhere, and they have always been, and still are, highly debated. Opponents think it undermines the market mechanism, increases poverty and unemployment among low-skilled workers and threatens businesses that cannot afford the higher costs induced by the minimum wage. Conversely, supporters believe that it increases the standard of living for those workers, reduces inequality and poverty and therefore brings about more justice in income. ${ }^{1}$ One of the last countries having introduced the minimum wage so far is Germany, where it was enforced in 2015, starting with a rather high level of $€ 8.50$, which was gradually increased to currently $€ 9.35$ and is about to be increased further to $€ 9.80$ in January 2021.

For its supporters, the minimum wage is hailed as a kind of universal antidote to all evils of global capitalism, which affects poorly skilled people in developed countries, because their jobs or job opportunities move toward emerging (or rather emerged) economies, in particular in Asia, while the well-educated in upper income segments keep on benefitting. In modern Western societies, the widening gap between rich and poor is perceived as a case of injustice and as a huge social and economic problem, which in some sense it certainly is. Unskilled work can be done by anyone, and if labor is cheaper in other parts of the world, those jobs move away from affluent, high-wage to low-wage countries, leaving the not so well-off in the rich countries behind.

\footnotetext{
${ }^{1}$ https://worldpopulationreview.com/countries/minimum-wage-by-country/
} 
This is a fact. However, it is also a normal and natural process in a market economy. And even though the social problem cannot and should not be denied, low-wages indicate a gap between supply and demand of unskilled or low-skilled work, which cannot and should not be denied either. It could be understood as a sign that especially young people, who have to think about how to make a living in their future workinglives, have to orient themselves toward job opportunities as well as the skills and education that are needed to be able to grasp those opportunities.

As far as the long-term unemployed are concerned, they certainly need support. Hence, it is not the question, whether society has to do something about their situation, but how this should be done. Establishing a minimum wage is one way, subsidizing low income from labor with additional transfers is another. The latter strategy has been favored mostly by economists, the former by the German trade union federation $(\mathrm{DGB})^{2}$ in their campaign for the minimum wage, in which they championed ten key arguments ${ }^{3}$ of which three are of particular interest:

- Minimum wages would prevent "wage poverty" and make sure that workers do not depend on additional subsidies.

- Minimum wages would relieve the federal budget, because it is the duty of companies to provide high enough wages, not the duty of the government to support workers.

- Minimum wages would ensure justice by stopping the downward spiral of wages.

These arguments concern both positive and normative aspects. From a normative point of view, it is argued that poverty should not be understood in terms of total income, but in terms of earned wages. According to this (new) concept of "wage poverty," transfer payments do not count; it is rather the earned wages as such that should get workers above the culturally agreed minimum livelihood. If someone works fulltime and delivers decent work, he or she should earn a decent wage (in accordance also with the third argument).

This line of reasoning is problematic insofar as in a market economy, prices are not meant to be just. They are meant to be efficient (while the issues of justice and efficiency are systematically decoupled). The concept of a "just price" relates to ancient and scholastic conceptions of the economy and simply does not fit into the modern notion of markets, where prices basically have a steering function. They should indicate where to move productive resources. High prices indicate scarcity of the respective goods and services, while low prices indicate overabundance. Fairness, for its part, is provided in two ways: first by setting rules against exploitation, child labor and so forth that apply to all and are built into the market order, second by redistributing income through taxation and subsidies.

As to the positive analysis, it is a market-economic truism, that defining a lower bound for prices (here: wages) reduce demand (here: for low-skilled labor), unless price elasticity is zero or

\footnotetext{
${ }^{2}$ The abbreviation stands for "Deutscher Gewerkschaftsbund."

${ }^{3}$ https://www.dgb.de/schwerpunkt/mindestlohn/hintergrund/argumente
}

close to zero. In principle, demand is therefore negatively affected by minimum prices above the market price. This is true, even if in reality negative employment effects may not show up or may not be significant. High growth rates may compensate the negative effect, and if the elasticity of demand is (close to) zero, a minimum wage may merely set a new reference point without any negative employment effect. Furthermore, minimum wages might not have detrimental effects, if low wages only result from a low bargaining power of the workers and where jobs cannot be displaced (as e.g., in the case of waiters and hairdressers).

Hence, the crucial question is not, whether a person is in favor of or opposed to minimum wages, but how she construes the pros and cons and, in particular, whether and to what extent they...

- misconstrue the causal effects of minimum prices in general, with the possibly paradoxical result that the creation of much needed jobs in the low-wage sector is disincentivized.

- Confound means and ends, because the minimum wage is meant to solve the justice problem of wealth distribution and the allocation of income within the market framework, while markets are meant to solve the efficiency problem of wealth creation and the allocation of factors of production.

The first fallacy gets the causal relations wrong, the second is an example of a category error. Both errors are possibly fatal, because they could take us to jump out of the frying pan into the fire, i.e., to create more harm out of good intentions. As for Germany, the number of workers who have to be subsidized in addition to their wage income has only been slightly reduced, because only 3 per cent of those who receive the minimum wage are fulltime working singles. And while the hourly wages have been augmented, working hours have been diminished so that a 14 percent increase in terms of hourly wages in the relevant group results in only a 4 percent increase in monthly wages. While employment remained largely stable or even increased slightly between 2016 and 2017 in industries not affected by the minimum wages, it was reduced significantly in those affected by the minimum wage (Mindestlohn-Kommission, 2018). By and large the effects so far have been only moderate, but as we know from recent research, this is partly due to substantial non-compliance. Out of a total of roughly 4 million workers who are eligible for the minimum wage, 750,000 are paid less than the minimum wage (see Caliendo et al., 2019). Based on calculations of the true hourly wage that is paid, the German Institute for Economic Research (Fedorets et al., 2020) even reports that we end up with 2.4 million workers who are paid below the minimum wage in their main occupations, ${ }^{4}$ even though they concede that wage inequality has declined in Germany since 2006.

\section{Thinking Critically About the Minimum Wage}

As one can easily see, the task critical thinkers with an economics background face is manifold. Concerning the status quo, they first

\footnotetext{
${ }^{4}$ If sideline jobs are included, the number rises to 3.8 million employees paid below the minimum wage (Fedorets et al., 2020).
} 
have to reconstruct, analyze, and evaluate the reasoning that had led to the introduction of the minimum wage. Four decisive parts can be extracted in this respect:

1. Identifying the underlying problem and its epistemic domain: positive (explanatory), prescriptive (instrumental), or normative (ethical).

2. Understanding the minimum wage as a possible solution to this problem.

3. Deriving consequences based on background knowledge or assumptions.

4. Gathering evidence, weighing pros and cons, and judging whether the minimum wage is an acceptable solution or not.

(1) It should be clear that the basic problem at issue is that wages are perceived to be too low from an ethical point of view. While it is questionable whether the problem persists in the light of additional transfer payments by the government, at least for the DGB the fundamental issue is wage poverty, which is held to be unjust. At least for the DGB this is taken for granted, so that they do not see an ethical problem of how to determine what is just, but an instrumental one of how to implement justice, as they understand it. Ennis (1996) calls this step identifying the focus. Jenicek and Hitchcock (2005) refer to this step as problem identification and analysis (see Hitchcock, 2017).

(2) Setting a minimum wage is the straightforward answer to this problem. While there might be other possible solutions (including the pre-existing one of topping up wages by governmental subsidies), wages lower than the minimum wage will certainly be pushed up, as long as employers comply with the rule.

(3) Apart from rising hourly wages, critical thinkers might infer that employers could try to formally reduce working hours (while the overall workload for each worker remains essentially the same), or that they might reduce jobs as a reaction to higher costs. Conversely, they might reckon that if margins for employers are sufficiently high, no jobs would be lost, and that only the overall surplus would be divided differently between workers and employers.

(4) Based on the aspects taken into account and the evidence gathered in their respect, beliefs have to be formed or updated, which ultimately take reasoners to their final conclusion. Accordingly, they might speak out for or against the minimum wage, or they might remain indifferent.

Whatever they think after this analysis, they will either remain with or encounter a new problem, when they are exposed to the report of the minimum wage commission. Advocates of the minimum wage must face the (possible) problem of inefficiency owing to non-compliance and job losses. Hence, they will find themselves in a situation where the problem of implementing "just wages" is either not solved (owing to various forms of noncompliance) or that a new technological problem emerges, namely that of creating new jobs or preventing job losses. Opponents may find that this problem is automatically solved, if the minimum wage is withdrawn. However, they face a problem of injustice and see themselves in a situation, where they have to be able to offer a solution to solve the original problem in a different way (other than the minimum wage). The identification and specification of this problem is the crucial step that has to be taken by both advocates and opponents of the minimum wage.

\section{AN INFERENTIAL FRAMEWORK FOR PROCESSES OF CRITICAL THINKING}

\section{Reasoning-Based Dimensions of Critical Thinking}

The four parts of CT explained in section "Thinking Critically About the Minimum Wage" correspond by and large to the reasoning-related dimensions described in ZlatkinTroitschanskaia et al. (2019): Recognizing and evaluating arguments and making decisions ${ }^{5}$ and recognizing and evaluating the consequences of decisions. An inferential reconstruction can further clarify the meaning and different aspects of processes like "decision making." In addition to the reasoning-related dimensions, there are also dimensions of critical thinking, which concerns the research and evaluation of information from multiple sources and the examination of sources [e.g., recognizing and evaluating information (Zlatkin-Troitschanskaia et al., 2019) or location, evaluation and integration/synthesis of information (see Leu et al., 2014)]. The skills related to these dimensions are particularly relevant if the task involves information from online sources, which do not have to undergo an editorial process and where the sources of the information as well as the distributors of the information may be unknown.

In the present article, however, we focus only on reasoningrelated dimensions, since the conceptualization and assessment of the reasoning-related dimension of $\mathrm{CT}$ requires further clarification, which can be delivered by the inferential framework (as we try to show in the following subsections). First, the inferential taxonomy provides a unified framework by which CT-relevant cognitive activities (like interpretation, analysis, inference, evaluation, explanation etc.; see Dormann et al., 2018) can be subsumed under specific inferences. Second, distinctive skill categories can be defined. For instance, the category "inference" (sensu Dormann et al., 2018), which includes querying evidence, conjecturing alternatives, drawing conclusions, can be specified: Querying evidence is part and parcel of induction, conjecturing alternatives concerns abduction, ${ }^{6}$ while drawing conclusions is a particular step in all kinds of inferences (see section "Inferential Processes"). In effect, the individual skills can be localized in the dynamics of an inferential cycle, which allows the explication of inaccurate cognitive activities as errors of reasoning. Finally, validity conditions for each inference can be specified. In the case of induction, the validity criterion also depends on the domain of reasoning. Thus, validity conditions can also be differentiated by domain (positive, prescriptive, or normative). As a consequence, the assessment of CT can be based

\footnotetext{
${ }^{5}$ Note, that Zlatkin-Troitschanskaia et al. (2019) merged dimension "recognizing and evaluating information" and dimension "recognizing and evaluating arguments and making decisions" into one dimension after statistical analyses.

${ }^{6}$ da Silva Almeida and Rodrigues Franco (2011) denote this as the creative facet (see section "Introduction").
} 
on the inferential processes individuals undergo and the extent to which their conclusions are warranted.

The inferential framework applies to individuals' reasoning processes such as the derivation of implications and consequences or the development of sound arguments (subsumed as synthetic dimensions of CT by Liu et al., 2014) as well as the comprehension and evaluation of arguments inferred by others (analytical dimensions of CT; ibid.).

\section{The Inferential Triad}

As opposed to the "consensus list of critical thinking skills," which was reported in the introduction, we believe that all critical thinking is inferential in some sense and takes place in the context of certain inferences. It has to be taken into account, of course, that Dormann et al. (2018) understanding of "inferences" is narrower than the present one and only pertains to evidential reasoning. Conversely, the inferential theory of learning can be applied to all issues of analysis, evaluation, and problem solving, and integrate these issues systematically within an overall context of inferential reasoning. As a consequence, different aspects of critical thinking are then understood and addressed as different aspects of inferential reasoning as such.

In the following section, we present this inferential framework and explicate the mental processes underlying critical thinking in detail. This yields a view of critical thinking processes that is both differentiated and integrated, and that allows us to account for correct and incorrect reasoning with respect to specific reasoning processes. It also allows us to distinguish different kinds of fallacies as well as specific clues for constructive support. And it provides general guidelines for the initiation of reasoning processes and the promotion of critical thinking skills.

The inferential theory of learning rests on C. S. Peirce's pragmatist theory of knowledge creation and the inferential processes he distinguishes. In particular, Peirce has introduced the concept of abduction to modern epistemology and philosophy of science and created a whole theory of how knowledge is acquired from the first perception of a problem to its solution. The following model of these inferences was first suggested in Minnameier (2004). It shows that the three inferences of abduction, deduction, and induction form a recursive triad (Figure 1).

The triad begins at $t_{0}$ with the surprising problem, and matches very well with Peirce's description in (CP 5.171). ${ }^{7}$ The surprising facts then call for an explanation, and abduction (at least in explanatory abduction) describes the process of developing potential explanations, which are subsequently examined by deduction and induction.

What is particular about this model is that the inductive arrow points back to the starting point, rather than to the

\footnotetext{
7 "Abduction is the process of forming an explanatory hypothesis. It is the only logical operation which introduces any new idea; for induction does nothing but determine a value, and deduction merely evolves the necessary consequences of a pure hypothesis. Deduction proves that something must be; Induction shows that something actually is operative; Abduction merely suggests that something may $b e$. Its only justification is that from its suggestion deduction can draw a prediction which can be tested by induction, and that, if we are ever to learn anything or to understand phenomena at all, it must be by abduction that this is to be brought about" (CP 5.171 [1903]).
}

theory (which is either accepted or rejected as the outcome of induction). The reason is that induction cannot "prove" a theory, even if the evidence is decisive. Therefore, the acceptance of a theory is interpreted in the sense of projecting the content of the theory onto its cases - the original surprising one, the tested ones, and the untested ones at present, in the past, and in the future. This implies that any theory is implicitly evaluated each time it is applied.

To be sure, the reasoning process as such starts even one step before abduction, so as to produce surprise (or a cognitive state equivalent to surprise). The "surprise" in this model comes as a "negative induction," which reveals that something expected is not actually the case. In other words, the theory and our current observations decohere. This decoherence is what generates a new abductive problem, and a successful abduction is understood as re-establishing coherence.

With regard to critical thinking the focus is on identifying problems and errors of reasoning, rather than the creative search for solutions that has just been mentioned in the preceding paragraph. However, the whole triad is important for critical thinking, because in order to reflect on minimum wages, critical thinkers have to comprehend the original problem minimum wages are meant to solve, understand how they should function, be able to derive deductive consequences based on their background knowledge and to evaluate that pros and cons based on what we know or on future empirical research to be carried out.

\section{Inferential Processes}

Inferences, whether abductive, deductive, or inductive, are cognitive processes with a definite beginning and a definite end. If we take, e.g., deduction as the most common inference, it starts from putting together a couple of premises, from which one then tries to derive necessary consequences, i.e., results that are implicit in the premises. Once we identify candidates for such results we have to judge, whether they really follow from the premises (because the moment of finding a result as such is a spontaneous event). If the result is judged valid, the process is terminated. Thus, the bare-bone structure of any inference consists of three distinctive steps that Peirce calls "colligation," "observation," and "judgment" (CP 2.442-444 [c. 1893]). ${ }^{8}$

\footnotetext{
8 "The first step of inference usually consists in bringing together certain propositions which we believe to be true, but which, supposing the inference to be a new one, we have hitherto not considered together, or not as united in the same way. This step is called colligation. The compound assertion resulting from colligation is a conjunctive proposition ... Colligation is a very important part of reasoning, calling for genius perhaps more than any other part of the process" (CP 2.442).
}

"An inference, then, may have but a single premiss, or several premises may be united by colligation. In the latter case, they form, when colligated, one conjunctive proposition. But even if there be but one premiss, the icon of that proposition is always more or less complex. The next step of inference to be considered consists in the contemplation of that complex icon, the fixation of the attention upon a certain feature of it, and the obliteration of the rest of it, so as to produce a new icon" (CP 2.443). "It thus appears that all knowledge comes to us by observation" (CP 2.444).

"Whenever one thing suggests another, both are together in the mind for an instant. In the present case, this conjunction is specially (sic!) interesting, and 


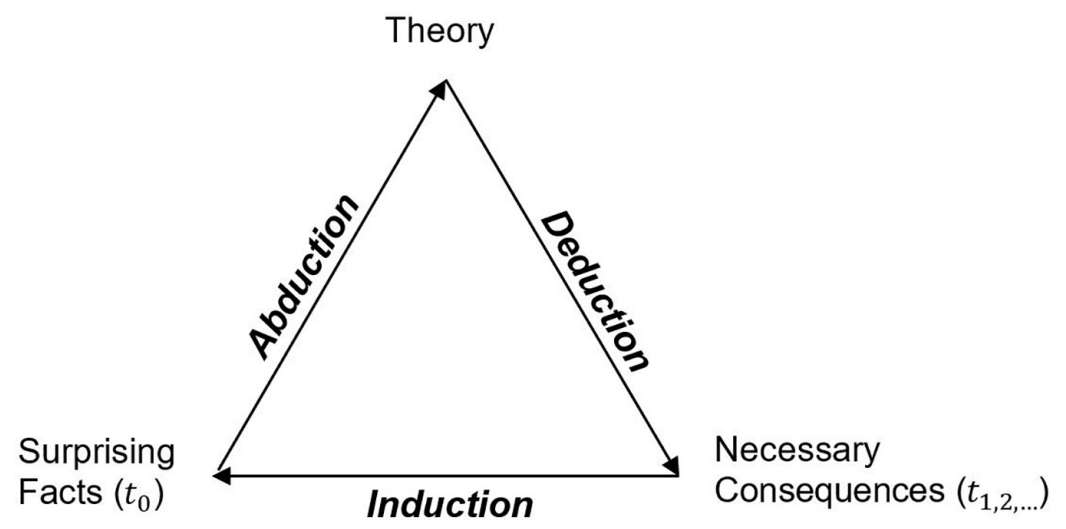

FIGURE 1 | The inferential triad.

Accordingly, any inference starts from the colligation of certain premises, from which conclusions are to be drawn. These premises are observed so as to produce some result and answer a specific question, which is the target of the inference. However, since every such result first springs to our minds spontaneously in the process of observation, it has to be followed by a judgment to make it a conclusion and in order to prevent spurious thoughts and mistakes. Such judgments are not to be misunderstood as meta-reflections or rule-following, but merely as satisfying the mind that the premises sanction the conclusion. Again, for abduction this means that the conclusion removes the incoherence inherent to the premises. If it does, the abduction is valid. A deductive inference is valid, if the conclusion is implied by the premises. Finally, validity of an inductive inference means that not only the empirical tests confirm the underlying theory, but that possible rival theories can also be rejected. As to this general understanding of inference (see also Stalnaker, 1987; Woods, 2013, 2017; Valaris, 2017; Hofmann, 2019).

Every inference must have a target, for without such a target it would be useless to engage in making the inference anyway. The target of abduction is to remove epistemic surprise and produce coherence. The target of deduction is to determine what follows necessarily from certain premises or assumptions by revealing their implications. The target of induction is to determine whether the underlying theory or action plan it to be accepted or rejected, albeit perhaps preliminary. The latter is also known as the "inference to the best explanation" (IBE) (Lipton, 2004; see also Minnameier, 2004, 2017, 2019; Yu and Zenker, 2018).

Induction, or IBE, leads to projecting the content of the theory onto all relevant cases (past, present, or future). And this is true in the positive case, where we accept the theory as well as in the negative case, where we just project its negation onto

in its turn suggests that the one necessarily involves the other. A few mental experiments... satisfy the mind that the one icon would at all times involve the other... Hence the mind is not only led from believing the premiss to judge the conclusion true, but it further attaches to this judgment another - that every proposition like the premiss, that is having an icon like it, would involve, and compel acceptance of, a proposition related to it as the conclusion then drawn is related to that premiss. [This is the third step of inference.]" (CP 2.444; emphasis). the cases (meaning that what the theory assumes is not true of those cases). Inductive judgments are always preliminary in the sense that every application of the theory might just as well challenge the theory as it might corroborate it. This is the essence of pragmatism. However, inductive judgments might also be preliminary in the sense of a tentative decision, especially when we are under pressure to act and have to make choices based on weak evidence.

\section{Domains of Reasoning}

Extending Peirce's analysis of explanatory reasoning, we can conceive of inferential reasoning in non-explanatory domains (Gabbay and Woods, 2005), in particular in the domains of prudential (or instrumental, strategic or technological) ${ }^{9}$ reasoning and ethical reasoning (Minnameier, 2017). The latter two forms might both be called normative, but in two different respects. Prudential reasoning concerns the question of how to reach a certain goal effectively. It looks for suitable means to reach specified ends. Conversely, ethical reasoning focuses on determining what would be suitable ends to pursue. Quite often we conflate these two distinct forms within the concept of normative statements as opposed to positive statements. The positive/normative-distinction is so commonplace, today, that we often fail to clearly separate instrumental reasoning from ethical reasoning. However, this is of vital importance with respect to the present subject matter, i.e., minimum wages, where both aspects are central, yet have to be kept strictly separate.

To our knowledge, the idea that the simple and strict positive/normative dichotomy is erroneous goes back to Putnam (2002). One of his main claims is "that the activity of justifying factual claims presupposes value judgments" (p. 137). In particular, every acceptance of a theory - by way of induction, as we might say - hinges on criteria for evaluation that we

${ }^{9}$ The concept of "prudence" is a technical term in philosophy. In particular, it is used to distinguish "moral" or "ethical" judgments from "prudential" ones (cf. e.g., Crisp, 2018). Both suggest courses or action, but the latter ones relate only to the interest of the agent. In everyday language they are also called "instrumental" or "strategic." "Technological" can also be used as a synonym, if its meaning is not restricted to the use of some kind of machinery, but covers means-end reasoning and optimization in general. 
use (whether we champion simplicity, coherence, predictive validity, or whatsoever, which are all values (cf. ibid., p. 142). Whichever criterion is chosen, we end up assigning a truth-value to the theory we evaluate. And within the frame of reference of positive - or call it "descriptive" or "explanatory" - reasoning and research we follow the regulative idea of truth.

Accordingly, we can distinguish three domains of reasoning that we could label

(i) positive/explanatory,

(ii) prescriptive/instrumental, and

(iii) normative/ethical

While positive (or explanatory) reasoning is guided by the regulative idea of truth, prescriptive (or instrumental) reasoning is guided by the regulative idea of "efficiency" or "effectiveness", ${ }^{10}$ and normative (or ethical) reasoning by that of "justice" (or the "good life," in general).

With respect to the problem at hand it has already been pointed out that the minimum wage can be analyzed and evaluated in terms justice as well as in terms of efficiency, and that critical thinkers would have to consider both independently. However, as far as we know, they do not seem to differentiate much. A study comparing economists' and laypeople's evaluation of labor market policies (Haferkamp et al., 2009) has revealed that most laypeople favor policies like the establishment of a general minimum wage and consider them both fair (more than 75\%) and efficient (more than 50\%), while almost all people with an economic background regard them as unfair and inefficient. Hence, a crucial element of critical thinking with respect to the minimum wage is to distinguish between the aspect of normativity (i.e., what one wants to achieve) and implementation (i.e., how it can best be achieved). Justice relates to the former, efficiency to the latter, because efficiency in terms of growth and economic prosperity provides the basis for a normatively motivated redistribution of wealth or resources.

\section{The Minimum Wage Task and Analysis}

In our study, we aim at describing critical thinking in terms of cognitive skills, as they are captured by the inferential learning theory. While this also encompasses forms of tacit knowing, like e.g., intuitive decision-making (see Hermkes, 2016; Minnameier, 2019), we concentrate on deliberative thinking in present study. Accordingly, we do not focus on issues like biased information and framing effects, but try to find out, how students actually think and reason based on the information presented to them. In particular, the strategy is to present mutually incompatible accounts of a certain subject matter, which in our case consists in the pros and cons of a general minimum wage. Critical thinkers

\footnotetext{
${ }^{10}$ There is a terminological problem, because "efficiency" has different uses. Here it is meant in the sense of means-end relationships where efficiency refers to optimality in terms of getting the most out of a specific input or reaching a pre-specified output with the minimum input. However, economists also use "efficiency" in terms of the best outcome for a group of people (as for instance in welfare economics). In this latter sense, "efficiency" belongs to normative reasoning in the context of the regulative idea of the good life (for a group of people), although not in the sense of justice. Hence, the "good life" is the broader notion, referring to either individuals, a group of individuals or from a transindividual point of view, where only the latter concerns "justice."
}

in our sense have to understand, analyze, and evaluate conflicting views on this particular issue.

The participants are Bachelor and Master students of economics. Bachelor students should already have successfully completed the introductory courses in economics (3rd semester and beyond). When designing the task, we are guided by the investigation of Zlatkin-Troitschanskaia et al. (2019): The minimum wage task is designed to be presented on a computer in a controlled setting. The stimulus material includes the following documents: (1) ten arguments pro minimum wage of the DGB, (2) a reply to the arguments, comprising ten counter-arguments, (3) report of the German commission on the minimum wage (Mindestlohn-Kommission, 2018), (4) chapters from a standard textbook on economics, including the following contents: Market forces of supply and demand, elasticity, efficiency of markets, labor market theory (pdf documents). Moreover, students are allowed to search for information on the internet. The response format is a written statement. The argumentation serves as a data basis for the rating. The task is processed as follows: First, students are presented the ten arguments of the DGB in favor of the minimum wage and asked to evaluate the claims critically. This analysis probes their critical thinking in terms of distinguishing domains (justice versus efficiency).

Next, students are confronted with the 2018 report of the German commission on the minimum wage (MindestlohnKommission, 2018) and allowed to search the internet for additional information. Their task at this stage is to determine what speaks in favor of the minimum wage and what against. Inasmuch as students are critical thinkers, they should not just decide for or against and then prop up and preserve their view (in the sense of immunizing it against counter-arguments), but should rather be capable of addressing the fundamental tradeoff between justice and efficiency that is at the heart of the debate.

The advantage of this tradeoff-constellation is not only that critical thinkers can prove how they not just immunize their own view, but take up valid critical aspects advanced by their opponents. Therefore, it does not really matter, whether an individual is for or against the minimum wage, because the situation for critical thinking would roughly be the same, just that the problem be inverse with respect to the two sides of the tradeoff:

- Those in favor of the minimum wage mainly focus on the justice aspect. However, they have to see and face the problem of inefficiency, that the minimum wage generally crowds out jobs (where more would be needed), or might entail non-compliance if it cannot be fully enforced.

- Those against the minimum wage focus on the efficiency aspect and the functioning of the market mechanism, but have to acknowledge and address the challenge of injustice.

In both cases, performances can be reconstructed as an inferential cycle. The inferential processes can be assessed according to the "reasoning"-related dimensions of CT (recognizing and evaluating arguments and making decisions; recognizing and evaluating the consequences of decisions). According to the fourpart model of critical thinking explicated in section "Thinking 
Critically About the Minimum Wage," students' reasoning includes

(1) identifying the domain in which the problem to be solved is located,

(2) understanding to what extent a minimum wage can be a possible solution,

(3) seeing consequences for the labor market or related to social justice,

(4) evaluating them in terms of justice and efficiency.

From an inferential point of view, both can be understood as abductively inferred conclusions, which represent solutions for a technological problem. The only difference is that the former try to find a technological solution to implement their idea of just wages, while the latter try to solve a problem of efficiency with respect to jobs and the economy in general.

From their respective theoretical points of view, both will have to consider economic theory as background knowledge and deduce consequences from them (based on what they know and what they find in the materials). Both advocates and opponents will finally have to address the above-mentioned difficulties in the inductive stage and acknowledge that there clearly are drawbacks that have to be addressed.

Regarding the processes of inferential reasoning explained in section "Inferential Processes," the abductive, deductive and inductive inferences can be described in more detail. Students have to colligate the content of the respective problem, in this case the justice problem, and understand the minimum wage as a solution to this problem (judgment step in abduction). From here, the critical evaluation of the minimum wage starts. In their deductive examination, they have to colligate not only the result of abduction (the problem and the minimum wage as solution), but also relevant information from the materials and from their previously acquired background knowledge. From this they have to derive - by way of observation and judgment - the various scenarios that follow from the respective assumptions. If given in the materials, they just have to comprehend these argumentations. The inductive part consists of colligating these deductive consequences as well as available empirical data or established facts and evaluating the minimum wage based on the evidence. Observation relates to taking notice of all the pros and cons and the probabilities of respective events or outcomes. In particular, it includes attending to the trade-off between justice and efficiency in the light of the evidence available. Finally, they have to judge whether to accept or reject the (general) minimum wage, or whether and why it has to remain an open question at the current state of affairs.

\section{TEACHING STRATEGIES TO PROMOTE CRITICAL THINKING - THE EVOCATION OF COGNITIVE CONFLICTS}

The inferential framework can be used as a foundation for the assessment of critical thinking skills because it reveals the cognitive deep structures that underlie the processes of argumentation and the students' engagement with the arguments of others. In addition to its relevance for the assessment of critical thinking, knowledge of cognitive deep structures can also be helpful when focusing on questions about appropriate teaching strategies. Abrami et al. (2008) review the effectiveness of instructional interventions to promote critical thinking skills. 117 studies with approximately 20,000 participants were examined for this purpose. As the authors summarize, critical thinking does not develop in an incidental manner alone, but requires appropriate teaching strategies and instructional methods. This accounts for the acquisition of critical thinking skills as well as for triggering of critical thinking in situ.

A suitable strategy to trigger critical thinking is the evocation of cognitive conflicts as explained above with respect to the minimum wage issue. Moreover, cognitive conflicts can serve to counteract the immunization of one's own position and can be an occasion to focus on the positions of other parties and to appreciate their arguments. This strategy can be placed in the context of constructivist learning theories, which consider disturbances to be the driving force for learning processes. Its appropriateness becomes obvious when one considers the explanations of critical thinking in the VALUE rubrics of the AAC\&U." Critical thinking is defined there as "the comprehensive exploration of issues, ideas, artifacts, and events before accepting or formulating an opinion or conclusion." 12

From a constructivist point of view, it can be argued that conceptual changes and the questioning of incoming "data" need an occasion. In Piagetian terms, what is needed is a disequilibrium between assimiliation and accommodation. Of course, dispositions such as open-mindedness or inquisitiveness (see Facione, 2000) can play a role and explain why some are generally more alert and inquisitive than others. Nevertheless, it would be erroneous to expect that each and every content presented would be generally doubted and called into question. For this to happen, events are needed that have the capacity to trigger critical thinking, which it does if it entails a disequilibration in the Piagetian sense. This is where cognitive conflicts come into play.

Whether critical thinking skills are applied in specific situations depends - apart from the motivation to use them ${ }^{13}$ on background knowledge and prior beliefs about the topic (Tarchi and Mason, 2020). Prior beliefs ${ }^{14}$ moderate the effect of critical thinking skills on the quality of arguments in the context of multiple text comprehension. Belief consistent information has a higher probability of being colligated, which may result (i) in a biased situational (mental) model in favor of the existing beliefs (see Maier and Richter, 2013) and (ii) in poor judgments. This is referred to as the "belief-consistency effect." In the case of minimum wages, students may, for example,

\footnotetext{
${ }^{11}$ https://www.aacu.org/value/rubrics/critical-thinking

${ }^{12}$ In inferential terminology, "comprehensive exploration" includes the abductive and deductive inferences, while "accepting an opinion or conclusion" refers to the final inductive judgment.

${ }^{13}$ For the motivational component of critical thinking see Facione et al. (1997), da Silva Almeida and Rodrigues Franco (2011); for the effects of motivation on students' performance see Liu et al. (2015), Braun (2019).

${ }^{14}$ E.g., about effects of vaccination.
} 
believe that the government is responsible for regulating markets when they cause (perceived) injustice. But they can also be convinced that regulations are detrimental interventions in markets that undermine the functioning of the market economy. As a consequence, depending on what beliefs are held, arguments for (or against) the minimum wage could either be appreciated and considered in one's reasoning or ignored and neglected. An explanatory model for the belief-consistency effect in the context of multiple text comprehension was presented by Richter and Maier (2017). As Richter and Maier put it, two processing steps take place in multiple text comprehension, which are associated with intuitive and deliberative thinking. The reference to intuitive and deliberative thinking is noteworthy, because it puts the model in the context of dual-process theories (see Kahneman, 2011). Dual-process theories are based on the assumption that there are two ways of thinking: a fast, intuitive and resource-saving way of thinking, and a slower, deliberative and more resourceintensive way of thinking. ${ }^{15}$ As a consequence, the empirical findings can be interpreted as instantiations of general patterns of human thinking.

Bearing in mind that individuals tend to focus on beliefconsistent information and that one cannot expect that each and every content presented would be cast into doubt, the question arises of how students can be "stimulated" to think critically when the subject area actually requires critical thinking. Or to be more specific: How can students be encouraged to include information and appreciate arguments that do not fit their current point of view? A first step to answer this question the evoking of cognitive conflicts to trigger critical thinking will be outlined in the following. In this context, the concept of epistemic vigilance can be taken into account (see Stadtler et al., 2015). Vigilance, however, should not only be understood in the context of reasoning as a trait, but rather as a state of conflict within the intuitive system in situ. Emerging conflicts can trigger subsequent reasoning activities. The occurrence of such activities marks the transition to deliberative reasoning (system 2), which is guided by strategic objectives (or in the case of multiple-textcomprehension by reading goals such as defending one's own position or reading out of epistemic curiosity; see Richter and Maier, 2017, p. 152).

How can cognitive conflicts arise? Based on the distinction between intuition and deliberation, it can be said that intuitive judgments are sometimes hasty and biased (for a well-known example see "the bat-and-ball" problem; Kahneman, 2011). System 2 could intervene to correct the biases produced by system 1. But there is also another way in which system 1 itself can deal with such biased judgments. This is due to the fact that conflicts can arise between prior beliefs and background knowledge, on the one hand, and intuitive judgments on the other hand. Both, the processing of background knowledge and intuitive decision-making are carried out non-deliberatively in system 1. As Trémolière and De Neys (2014) put it, "such a conflict with our background knowledge will decrease the appeal

\footnotetext{
${ }^{15}$ The various approaches differ in particular in the conceptualization of the interaction between the two ways of thinking. A prominent theory is the interventionist approach of Kahneman (2011). System-1 thinking is assumed to be the default mode, system 2 intervenes especially when cognitive conflicts occur.
}

of the substituted response and might thereby actually help people to reason better" (p. 487).

However, how can individuals notice such conflicts in the first place? A possible explanation given by Trémolière and De Neys (2014) is that the conflict leads to disfluency. The disturbed fluency serves as a signal, shifting the salience from the intuitively processed content to the conflict. As research on human intuition indicates, processing in system 1 and epistemic feelings are strongly intertwined (Schwartz, 1990; Koriat, 2000; McDermott, 2004; Proust, 2015). For example, feelings of fluency inform the individual whether cognitive processing is flowing or stagnating. Moreover, the monitoring function of epistemic feelings not only relates to the intuitive processes themselves, but also to the results of these processes (e.g., feelings of rightness, coherence, or uncertainty). As Proust (2015) states, the feelings' "valence and intensity tell the agent whether she should accept or reject a cognitive outcome" (p. 6).

The findings of Maier and Richter (2013) as well as those of Trémolière and De Neys (2014) point to the same "mechanism" in system 1. However, there is a main difference between the studies. Richter and Maier (2017) focus on the negative influence of background knowledge (and topic-related beliefs). According to the text-belief consistency effect, the "background" impedes a more elaborate text comprehension. In contrast, Trémolière and De Neys (2014) focus on the case where background knowledge plays a positive role in reasoning by preventing biased judgments. The latter is of particular interest for our task concerning the minimum wage in two respects:

(1) Economic content knowledge matters. Cognitive conflicts, which can trigger critical thinking processes, do not only arise when students begin to reflect on intuitive judgments, but already occur in the course of intuitive processing. However, to cause such conflicts, background knowledge is required. Since the processes take place within system 1, tacit knowledge (acquired e.g., through participation in a community of practice) can also be part of the knowledge base.

(2) If an uncritical and one-sided reception of a party's point of view occurs, or if that party just tries to persuade the addressee, then the evocation of cognitive conflicts can help to "stimulate" critical thinking. According to the inferential approach, such a judgment can be the result of an inductive inference at the end of the inferential cycle. A cognitive conflict should therefore be understood as instigating and motivating a new cycle.

It is worth mentioning that external "stimulation" is only one way to induce cognitive conflicts. The occurrence of cognitive conflicts can also be caused intrinsically. In our case of the minimum wage, this occurs when students, having argued either for the minimum wage as a solution to the justice problem or against it because of the efficiency problem, acknowledge ${ }^{16}$ that there are relevant drawbacks that have to be addressed. With this problem in mind, there would be a reason for students to

${ }^{16}$ Note that "acknowledge" can also be understood in terms of system-1 processes and does not necessarily have to aim at a deliberative process. 
initiate another inferential cycle and find an integrated solution (as outlined in section "The Case of the Minimum Wage"). But of course, there is no certainty that this will happen. Richter and Maier (2017) point out that the occurrence of a conflict does not necessarily mean that a new cycle is initiated. Students may perceive the conflict, but they can still ignore it. This leads to the question of how salient a conflict has to be for the students to start engaging it its solution. This can currently be regarded as an open empirical question.

\section{CONCLUSION}

Focusing on the example of the minimum wage, we have elaborated on how to engage critically with a controversial and much debated topic. An inferential framework was presented that enables us to reconstruct the cognitive deep structure of reasoning processes when arguing for or against minimum wages. Thus, the foundation has been laid for empirical studies to follow, in which students' critical thinking skills can be assessed.

\section{REFERENCES}

Abrami, P. C., Bernard, R. M., Borokhovski, E., Wade, A., Surkes, M. A., Tamin, R., et al. (2008). Instructional interventions affecting critical thinking skills and dispositions: a stage 1 Meta-analysis. Rev. Educ. Res. 78, 1102-1134. doi: $10.3102 / 0034654308326084$

Braun, H. (2019). Performance assessment and standardization in higher education: a problematic conjunction? Br. J. Educ. Psychol. 89, 429-440. doi: 10.1111/bjep. 12274

Caliendo, M., Schröder, C., and Wittbrodt, L. (2019). The causal effects of the minimum wage introduction in Germany - An overview. Ger. Econ. Rev. 20, 257-292. doi: 10.1111/geer.12191

Crisp, R. (2018). "Prudential and moral reasons," in The Oxford Handbook of Reasons and Normativity, ed. D. Star (Oxford: Oxford University Press), 800820. doi: 10.1093/oxfordhb/9780199657889.013.35

da Silva Almeida, L., and Rodrigues Franco, A. H. (2011). Critical thinking: its relevance for education in a shifting society. Rev. Psicol. 29, 175-195.

Dormann, C., Demerouti, E., and Bakker, A. (2018). "A model of positive and negative learning. Learning demands and resources, learning engagement, critical thinking, and fake news detection," in Positive Learning in the Age of Information: A Blessing or a Curse?, eds O. Zlatkin-Troitschanskaia, G. Wittum, and A. Dengel (Dordrecht: Springer), 315-346. doi: 10.1007/978-3-658-195670_19

Ennis, R. (1987). "A taxonomy of critical thinking abilities and dispositions," in Teaching Thinking Skills: Theory and Practice, eds J. Baron and R. Sternberg (New York: W. H. Freeman), 9-26.

Ennis, R. (1996). Critical Thinking. Upper Saddle River: Prentice-Hall.

Ennis, R. (2011). Critical thinking. Refl. Perspect. 26, 4-18. doi: 10.5840/ inquiryctnews 20112613

Facione, P. A. (2000). The disposition toward critical thinking: its character, measurement, and relationship to critical thinking skill. Informal Log. 20, 61-84. doi: 10.22329/il.v20i1.2254

Facione, P. A., Facione, N. C., and Giancarlo, C. A. (1997). "The motivation to think in working and learning. in Preparing Competent College Graduates," in Setting New and Higher Expectations for Student Learning, ed. E. Jones (San Francisco, CA: Jossey-Bass Publishers), 67-79. doi: 10.1002/he.36919969608

Fedorets, A., Grabka, M. M., Schröder, C., and Seebauer, J. (2020). Lohnungleichheit in Deutschland sinkt. DIW Wochenbericht 87, 92-97. doi: 10.18723/diw_wb:2020-7-1

Gabbay, D. M., and Woods, J. (2005). A Practical Logic of Cognitive Systems. Volume 2: The Reach of Abduction - Insight and Trial. Amsterdam: Elsevier. doi: 10.1016/S1874-5075(05)80020-8
Depending on the reasoning dynamics (e.g., the appearance of reasoning errors) and existing student dispositions, instructional interventions can take place. One teaching strategy to encourage critical thinking is the evocation of cognitive conflicts. With the reconstructed deep structure of the students' cognitive processes, "cognitive activation" can be geared to each student's mindset and in an adaptive way. The effectiveness of such interventions, e.g., against immunization or students' proneness to persuasive agitation, can thus be investigated in more detail.

\section{AUTHOR CONTRIBUTIONS}

GM has presented and analyzed the case of the minimum wage, delivered the inferential approach and the inferential reconstruction of the task and instances of critical thinking in dealing with the case. $\mathrm{RH}$ has contributed the teaching strategies to promote critical thinking and parts of the inferential reconstruction of the problem. Both authors contributed to the article and approved the submitted version.

Haferkamp, A., Fetchenhauer, D., Belschak, F., and Enste, D. (2009). Efficiency versus fairness: the evaluation of labor market policies by economists and laypeople. J. Econ. Psychol. 30, 527-539. doi: 10.1016/j.joep.2009.03.010

Hermkes, R. (2016). "Perception, abduction, and tacit inference," in Model-Based Reasoning in Science and Technology - Logical, Epistemological, and Cognitive Issues, eds L. Magnani and C. Casadio (Heidelberg: Springer), 399-418. doi: 10.1007/978-3-319-38983-7_22

Hitchcock, D. (2017). “Critical thinking as an educational ideal," in On Reasoning and Argument. Essays in Informal Logic and on Critical Thinking, ed. D. Hitchcock (Cham: Springer Nature Switzerland), 477-497. doi: 10.1007/9783-319-53562-3_30

Hofmann, F. (2019). How to know one's experiences transparently. Philos. Stud. 176, 1305-1324. doi: 10.1007/s11098-018-1064-0

Jenicek, M., and Hitchcock, D. (2005). Evidence-Based Practice: Logic and Critical Thinking in Medicine. Chicago: AMA Press.

Kahneman, D. (2011). Thinking, Fast and Slow. New York, NY: Farrar, Straus and Giroux.

Koriat, A. (2000). The feeling of knowing: some metatheoretical implications for consciousness and control. Cons. Cogn. 9, 149-171. doi: 10.1006/ccog.2000. 0433

Leu, D. J., Kiili, C., Forzani, E., Zawilinski, L., McVerry, J. G., and O’Byrne, W. I. (2014). The new literacies of online research and comprehension: rethinking the reading achievement gap. Read. Res. Q. 50, 37-59. doi: 10.1002/rrq.85

Lipton, P. (2004). Inference to the Best Explanation, 2nd Edn. London: Routledge. doi: 10.4324/9780203470855

Liu, O. L., Frankel, L., and Roohr, K. C. (2014). Assessing critical thinking in higher education: current state and directions for next-generation assessments. ETS Res. Rep. Ser. 1, 1-23. doi: 10.1002/ets2.12009

Liu, O. L., Rios, J. A., and Borden, V. (2015). The effects of motivational instruction on college students' performance on low-stakes assessments. Educ. Assess. 30, 79-94. doi: 10.1080/10627197.2015.1028618

Magnani, L. (2009). Abductive Cognition. The Epistemological and Eco-Cognitive Dimension of Hypothetical Reasoning. Berlin: Springer. doi: 10.1007/978-3-64203631-6

Magnani, L. (2018). The urgent need of a naturalized logic. Philosophies 3:44. doi: 10.3390/philosophies3040044

Maier, J., and Richter, T. (2013). Text-belief consistency effects in the comprehension of multiple texts with conflicting information. Cogn. Instr. 31, 151-175. doi: 10.1080/07370008.2013.769997

McDermott, R. (2004). The feeling of rationality: the meaning of neuroscientific advances for political science. Perspect. Polit. 2, 691-706. doi: 10.1017/ S1537592704040459 
Mindestlohn-Kommission (2018). Zweiter Bericht zu den Auswirkungen des gesetzlichen Mindestlohns: Bericht der Mindestlohnkommission an die Bundesregierung nach $\$ 9$ Abs. 4 Mindestlohngesetz. Available online at: https://www.mindestlohn-kommission.de/DE/Bericht/pdf/Bericht2018.html? nn=7081728 (accessed July 17, 2020).

Minnameier, G. (2004). Peirce-Suit of Truth - Why inference to the best explanation and abduction ought not to be confused. Erkenntnis 60, 75-105. doi: 10.1023/B:ERKE.0000005162.52052.7f

Minnameier, G. (2017). "Forms of abduction and an inferential taxonomy," in Springer Handbook of Model-Based Reasoning, eds L. Magnani and T. Bertolotti (Dordrecht: Springer), 175-195. doi: 10.1007/978-3-319-30526-4_8

Minnameier, G. (2019). "Re-reorienting the logic of abduction and the naturalization of logic," in Natural Arguments: A Tribute to John Woods, eds D. Gabbay, L. Magnani, W. Park, and A. V. Pietarinen (London: College Publications), 353-374.

Oser, F. (2018). "Positive learning through negative learning. The wonderful burden of PLATO," in Positive Learning in the Age of Information: A Blessing or a Curse?, eds O. Zlatkin-Troitschanskaia, G. Wittum, and A. Dengel (Dordrecht: Springer), 363-370. doi: 10.1007/978-3-658-19567-0_21

Proust, J. (2015). The Representational Structure of Feelings. Available online at: https://open-mind.net/papers/the-representational-structure-of-feelings (accessed July 17, 2020).

Putnam, H. (2002). The Collops of the Fact/Value Dichotomy and Other Essays. Cambridge, MA: Harvard University Press.

Richter, T., and Maier, J. (2017). Comprehension of multiple documents with conflicting information: a two-step model of validation. Educ. Psychol. 52, 148-166. doi: 10.1080/00461520.2017.1322968

Roetzel, P. G. (2019). Information overload in the information age: a review of the literature from business administration, business psychology, and related disciplines with a bibliometric approach and framework development. Bus. Res. 12, 479-522. doi: 10.1007/s40685-018-0069-z

Schwartz, N. (1990). "Feelings as information: Informational and motivational functions of affective states," in Handbook of Motivation and Cognition: Foundations of Social Behavior, Vol. 2, eds E. T. Higgins and R. M. Sorrentino (New York, NY: Guilford), 527-651.

Shavelson, R. J., Zlatkin-Troitschanskaia, O., Beck, K., Schmidt, S., and Marino, J. P. (2019). Assessment of university students' critical thinking: next generation performance assessment. Int. J. Test 19, 337-362. doi: 10.1080/15305058.2018. 1543309
Stadtler, M., and Bromme, R. (2013). Multiple document comprehension: an approach to public understanding of science. Cogn. Instr. 31, 122-129. doi: 10.1080/07370008.2013.771106

Stadtler, M., Paul, J., Globoschütz, S., and Bromme, R. (2015). Watch out! An Instruction Raising Students' Epistemic Vigilance Augments Their Sourcing Activities. Mind, Technology, and Society. Austin: Cognitive Science Society, 2278-2283.

Stalnaker, R. C. (1987). Inquiry. Cambridge, MA: A Bradford Book.

Tarchi, C., and Mason, L. (2020). Effects of critical thinking on multiple-document comprehension. Eur. J. Psychol. Educ. 35, 289-313. doi: 10.1007/s10212-01900426-8

Trémolière, B., and De Neys, W. (2014). When intuitions are helpful: Prior beliefs can support reasoning in the bat-and-ball problem. J. Cogn. Psychol. 26, 486-490. doi: 10.1080/20445911.2014.899238

Valaris, M. (2017). What reasoning might be. Synthese 194, 2007-2024. doi: 10. 1007/s11229-016-1034-z

Woods, J. (2013). Errors of Reasoning: Naturalizing the Logic of Inference. London: College Publications.

Woods, J. (2017). "Reorienting the logic of abduction," in Handbook of ModelBased Science, eds L. Magnani and T. Bertolotti (Dordrecht: Springer), 137-150. doi: 10.1007/978-3-319-30526-4_6

Yu, S., and Zenker, F. (2018). Peirce knew why abduction isn't IBE: a scheme and critical questions for abductive argument. Argumentation 32, 569-587. doi: $10.1007 /$ s10503-017-9443-9

Zlatkin-Troitschanskaia, O., Shavelson, R. J., Schmidt, S., and Beck, K. (2019). On the complementarity of holistic and analytic approaches to performance assessment scoring. Br. J. Educ. Psychol. 89, 468-484. doi: 10.1111/bjep. 12286

Conflict of Interest: The authors declare that the research was conducted in the absence of any commercial or financial relationships that could be construed as a potential conflict of interest.

Copyright (c) 2020 Minnameier and Hermkes. This is an open-access article distributed under the terms of the Creative Commons Attribution License (CC BY). The use, distribution or reproduction in other forums is permitted, provided the original author(s) and the copyright owner(s) are credited and that the original publication in this journal is cited, in accordance with accepted academic practice. No use, distribution or reproduction is permitted which does not comply with these terms. 